\title{
Influence of Species, Geographic Location, Seasonal Variation and Extraction Method on the Fucoidan Yield of the Brown Seaweeds of Gulf of Mannar, India
}

\author{
V. RANI*, R. J. SHAKILA, P. JAWAHAR AND A. SRINIVASAN \\ Fisheries College and Research Institute, Tamil Nadu Fisheries University, Thoothukudi-628 008, India
}

Rani, et al.: Extraction Method on the Yield of Brown Seaweeds

\begin{abstract}
Brown seaweeds such as Sargassum wightii, S. oligocystum, Padina tetrastromatica and Turbinaria ornata were collected from two locations, Valinokkam and Hare Island in Gulf of Mannar, South East coast of India, to extract fucoidan and to analyse its variation in the yield for a period from July 2012 to January 2013. Water and acid extraction methods were followed to extract fucoidan. Water extraction yielded much higher fucoidan $(9.46 \pm 0.18)$ than acid method $(1.63 \pm 0.05)$. The yield of fucoidan also varied between the species, season and also geographic location. The highest yield was obtained from $P$. tetrastromatica $(9.46 \pm 0.18 \%)$ followed by $T$. ornata $(5.83 \pm 0.07 \%)$ and $S$. wightii $(3.90 \pm 0.05 \%)$. The yield was higher during maturation stage of the algae, which was September for $T$. ornata and $S$. wightii and January for P. tetrastromatica. Seaweeds found in shallow region gave higher yield (Hare Island) than those collected from more than $1 \mathrm{~m}$ depth in Valinokkam region. Compositional analysis of fucoidan revealed that sulphate content was higher in $T$. ornata $(24.27 \pm 0.85 \%)$ than $P$. tetrastromatica $(22.70 \pm 0.53 \%)$ and $S$. wightii $(18.73 \pm 0.82 \%)$. The fucose content was higher in $P$. tetrastromatica $(54.51 \pm 1.08)$ and lower in $S$. oligocystum (43.16 \pm 3.21$)$. Fourier transform infrared spectroscopy carried out for the two dominant species viz. $P$. tetrastromatica and $S$. oligocystum, showed a major broad band centered around $3448 \mathrm{~cm}^{-1}$ assigned to be due to hydrogen bonded $O-H$ stretching vibration. Another two bands appeared at $723 \mathrm{~cm}^{-1}$ and $601 \mathrm{~cm}^{-1}$ seem to be the characteristic of C-O-S stretching of sulphate group and $\mathrm{C}=\mathrm{C}-\mathrm{H}$ stretching vibration, respectively in both the species. However, the major differences among the species were the presence of a minor band at $2103.73 \mathrm{~cm}^{-1}$ in $P$. tetrastromatica and slight shifts noticed in sulphate group band.
\end{abstract}

Key words: Brown seaweeds, fucoidan yield, species, season, extraction method, characterization

Seaweeds are widely distributed along the Indian coastal region and in particular, brown seaweeds belonging to the group Phaeophyceae are dominant along the coast of Gulf of Mannar. Fucoidan is a sulphated polysaccharide found in the cell walls of several species of brown seaweed. In recent years, fucoidan has been isolated from different groups of brown seaweeds such as Fucales, Laminariales, Chordariales and Ectocapales ${ }^{[1]}$. Of which, brown seaweeds belonging to the group, Fucales are abundant in Indian coast and dominant in gulf of mannar region ${ }^{[2]}$. Many studies reveal that fucoidan exhibits versatile bio-active properties like antioxidative ${ }^{[3]}$, anticoagulant ${ }^{[4]}$, antimicrobia ${ }^{[5]}$, antitumor ${ }^{[6]}$ and immunomodulatory properties ${ }^{[7,8]}$.

Fucoidan was first isolated and named so by Kylin ${ }^{[9]}$. It has been extracted from seaweeds mainly by acid, alkali and solvent extraction ${ }^{[10]}$. Brown seaweeds produce families of sulphated fucoidans among other polysaccharides. They contain other sugars besides

*Address for correspondence E-mail: ranidarshini@gmail.com

January-February 2017
L-fucose, viz., D-xylose, D-galactose and D-glucuronic acid and additional sugars such as D-mannose and D-glucose have also appeared. However, sulphate is the major constituent along with small amounts of uronic acid and other sugars such as galactose, mannose, xylose and glucose ${ }^{[11]}$. In general, extraction of sulphated polysaccharides from seaweed is usually performed by using hot water, dilute acid, or dilute alkali. But all of these methodologies involve long extraction time and high volume of diluents ${ }^{[12-16]}$. Although various extraction methods have been widely used, the use of organic solvents was the most common method practiced widely ${ }^{[17]}$.

This is an open access article distributed under the terms of the Creative Commons Attribution-NonCommercial-ShareAlike 3.0 License, which allows others to remix, tweak, and build upon the work non-commercially, as long as the author is credited and the new creations are licensed under the identical terms

Accepted 08 January 2017

Revised 05 November 2016

Received 28 June 2016

Indian J Pharm Sci 2017;79(1): 65-71 
There are reports that the yield of fucoidan differ with the species, season and location of brown seaweeds; and also with the method of extraction. Further, the composition of fucoidan has been known to vary between the species of brown seaweeds. There is no report on the yield of fucoidan in the brown seaweed available along the coast of Gulf of Mannar at different species, season and location. Hence, in the present study; four different species of brown seaweeds predominantly available in two different locations of Gulf of Mannar during the peak season were analysed for fucoidan by following two different extraction methods.

\section{MATERIALS AND METHODS}

Four species of brown seaweeds viz. Sargassum wightii, S. oligocystum, Padina tetrastromatica and Turbinaria ornate, collected from the two different locations, Valinokkam (N:09 $\left.13.684, \mathrm{E}: 078^{\circ} 47.194\right)$ and Hare Island $\left(\mathrm{N}: 08^{\circ} 047.254^{\prime} \mathrm{E}: 078^{\circ}, 11.884\right)$ of Gulf of Mannar during the peak season from July 2012 to January 2013, were used to extract fucoidan by water and acid extraction.

\section{Water extraction method:}

The extraction of fucoidan was carried out as described by Yang et al. ${ }^{[15]}$ with a slight modification. The shade dried pulverized seaweed $(20 \mathrm{~g})$ was treated with $1 \mathrm{ml}$ of $85 \%$ ethanol with constant stirring for $12 \mathrm{~h}$ at room temperature in order to remove proteins and pigments. The ethanol-treated seaweed was washed with acetone, centrifuged at $10000 \mathrm{~g}$ for $10 \mathrm{~min}$ and then dried at room temperature. The dried biomass $(5 \mathrm{~g})$ was extracted with $100 \mathrm{ml}$ of distilled water at $65^{\circ}$ with continuous stirring for $1 \mathrm{~h}$ twice, and the extracts were combined. The combined extract was centrifuged at $10000 \mathrm{~g}$ for 20 min and the supernatant was treated with $1 \%$ of $\mathrm{CaCl}_{2}$ and kept at $4^{\circ}$ for overnight to precipitate the alginic acid after centrifugation at $10000 \mathrm{~g}$ for $20 \mathrm{~min}$ and the supernatant was collected. Ethanol was added into the supernatant to obtain a final ethanol concentration of $30 \%$, and the solution was placed at $4^{\circ}$ for $4 \mathrm{~h}$ in a chill cabinet. Again, the solution was centrifuged at $10000 \mathrm{~g}$ for $20 \mathrm{~min}$ to remove the remaining impurities as residue. Finally, ethanol was added into the supernatant to obtain a final ethanol concentration of $70 \%$, and then placed at $4^{\circ}$ overnight to precipitate out the intact fucoidan. After centrifugation at $10000 \mathrm{~g}$ for $15 \mathrm{~min}$, the residue fucoidan was washed with ethanol and acetone, and again dried at room temperature. The yield was calculated based on the following Eqn.: yield $(\%)=$ weight of the obtained fucoidan $(\mathrm{g}) /$ weight of the dried biomass $(\mathrm{g}) \times 100$.

\section{Acid extraction method:}

Acid extraction was followed as per the method described by Aloe ${ }^{[1]}$ with a slight modification. Dried seaweed powder $(120 \mathrm{~g})$ was treated with the solvent mixture consisting of ethyl alcohol, chloroform and distilled water at the ratio of $4: 2: 1$, with constant stirring at room temperature for $4 \mathrm{~h}$ in a magnetic stirrer. The supernatant was removed and the residue was dried overnight. Dried seaweed biomass was then treated with $0.03 \mathrm{M}$ hydrochloric acid $(\mathrm{HCl})$ at a ratio of 1:20 and heated at $90^{\circ}$ for $3 \mathrm{~h}$ in a water bath. The content was then centrifuged at $10000 \mathrm{~g}$ for $20 \mathrm{~min}$ at $4^{\circ}$ and the supernatant was collected. The residue was washed again with distilled water and centrifuged again. The supernatants were pooled and 99\% ethanol was added to obtain $60 \%$ ethanol concentration to precipitate out the crude fucoidan. The precipitate was washed with distilled water and immediately coagulated with $1 \mathrm{M}$ $\mathrm{CaCl}_{2}$ to remove the alginic acid. The sticky calcium alginate precipitate was discarded. The supernatant was again centrifuged at $10000 \mathrm{~g}$ for $20 \mathrm{~min}$ at $4^{\circ}$ to collect the fucoidan pellet. The pellet was again washed with alcohol and diethyl ether and dried overnight at $50^{\circ}$ to obtain fucoidan. The yield of fucoidan was calculated as described above.

\section{Characterization of fucoidan:}

For the characterization, fucoidan (10-15 $\mathrm{mg}$ ) was hydrolysed with $2 \mathrm{ml}$ of $4 \mathrm{~N} \mathrm{HCl}$ at $121^{\circ}$ for $2 \mathrm{~h}$ and then neutralized with $4 \mathrm{~N} \mathrm{NaOH}^{[8]}$. The sulphate content in the fucoidan was measured based on barium sulphate $\left(\mathrm{BaSO}_{4}\right)$ determination using barium chloride $\left(\mathrm{BaCl}_{2}\right)$ method described by Dodgson and Price ${ }^{[18]}$. Free fucose content in fucoidan was determined by cysteine-sulphuric acid method described by Dische and Shettles ${ }^{[19]}$. Total free sugars in the fucoidan were measured by the anthrone method ${ }^{[20]}$. The amount of protein in the fucoidan was determined by Bradford protein assay ${ }^{[21]}$.

The active components of the fucoidan were qualitatively determined by Fourier Transmission Infra-Red spectroscopy (FT-IR; Brucker Optik GmbH). Fucoidan (10-15 mg) was treated with 2-N trifluroacetic acid $(0.5$ $\mathrm{ml}$ ) at $121^{\circ}$ for $2 \mathrm{~h}$, in glass tubes sealed with $\mathrm{N}_{2}$, cooled and neutralised with $2 \mathrm{~N} \mathrm{NaOH}^{[22]}$. The frequency of the spectra analysis was set between 4000 and $400 \mathrm{~cm}^{-1}$ wave number and the vibration spectrum was recorded as a graphical chart. 


\section{Statistical analysis:}

All data were subjected to analysis of variance (ANOVA) using SPSS (SPSS 17.0 for window, SPSS Inc., Chicago, IL, USA) and the difference between the yield of fucoidan and its compositions were compared.

\section{RESULTS AND DISCUSSION}

Although seaweeds are available throughout the year in Gulf of Mannar coastal region, large quantities are collected only during the maturation stages of the respective algae. Brown seaweeds are particularly dominant along this coast during July to January ${ }^{[23]}$. In this study, four selected brown seaweeds, S. wightii, $S$. longifolium, $P$. tetrastromatica and $T$. ornate that are dominant along this coast were collected from two different locations, Hare Island and Valinokkam to examine the variation in the yield of fucoidan. Brown seaweed, $P$. tetrastromatica was dominant only in Hare Island, whereas $T$. ornata was abundant only in Valinokkam. The yield of fucoidan was found to be slightly higher from the respective seaweeds collected from Hare Island compared to those collected from Valinokkam, when subjected to water extraction $(\mathrm{P}>0.05)$, while significant variation was noticed with acid extraction $(\mathrm{P}<0.05)$ throughout the study period (figs. 1 and 2). Seaweeds in shallow region are exposed to sunlight during low tide and so would be expected to have more amount of fucoidan as they develop defence mechanisms against dryness ${ }^{[24]}$. Since, Hare Island is characterized with shallow coastal shore with the depth of less than 1 feet, where seaweeds are often exposed to sunlight during low tide, the weeds collected from this region gave higher yields when compared to those collected from Valinokkam, which has rocky shores with depth more than $1 \mathrm{~m}$. Another fact that supports this theory is that seaweeds when exposed to sunlight, their sugar content would increase and the UV rays of sunlight might destroy cellular constituents ${ }^{[25]}$.

Two extraction procedures were employed to extract fucoidan from brown seaweeds of Gulf of Mannar. The yield of fucoidan differed significantly $(\mathrm{P}<0.05)$ depending on the type of extraction procedure. Significantly higher yield of fucoidan was obtained through water extraction with a maximum of $9.46 \pm 0.18 \%$ in $P$. tetrastromatica followed by $5.83 \pm 0.07 \%$ in $T$. ornata and $3.28 \pm 0.04 \%$ in $S$. wightii. The yield of fucoidan extracted by acid method treatment was very low with a maximum yield of $1.63 \%$ in P. tetrastromatica and a minimum of $0.33 \%$ in $S$. oligocystum. It has been reported that the yield and chemical composition of fucoidan was strongly affected by the method of extraction ${ }^{[1]}$. In a similar study carried out by Mak ${ }^{[26]}$, three extraction methods such as water, acid and $\mathrm{CaCl}_{2}$ were compared, in which the highest yield was obtained with $\mathrm{CaCl}_{2}$ and the lowest with acid extraction. The present study demonstrated that water extraction was the most suitable method for extracting fucoidan from brown seaweeds, irrespective of the species.

Four brown seaweeds were examined for the yield of fucoidan during July 2012 to January 2013 i.e., the period of maturation of seaweeds. The yield of fucoidan was high during September and October in all species extracted with water. At Valinokkam, the yield of fucoidan gradually increased from $2.79 \pm 0.06$ to $3.28 \pm 0.04 \%$ for $S$. wightii during July to September

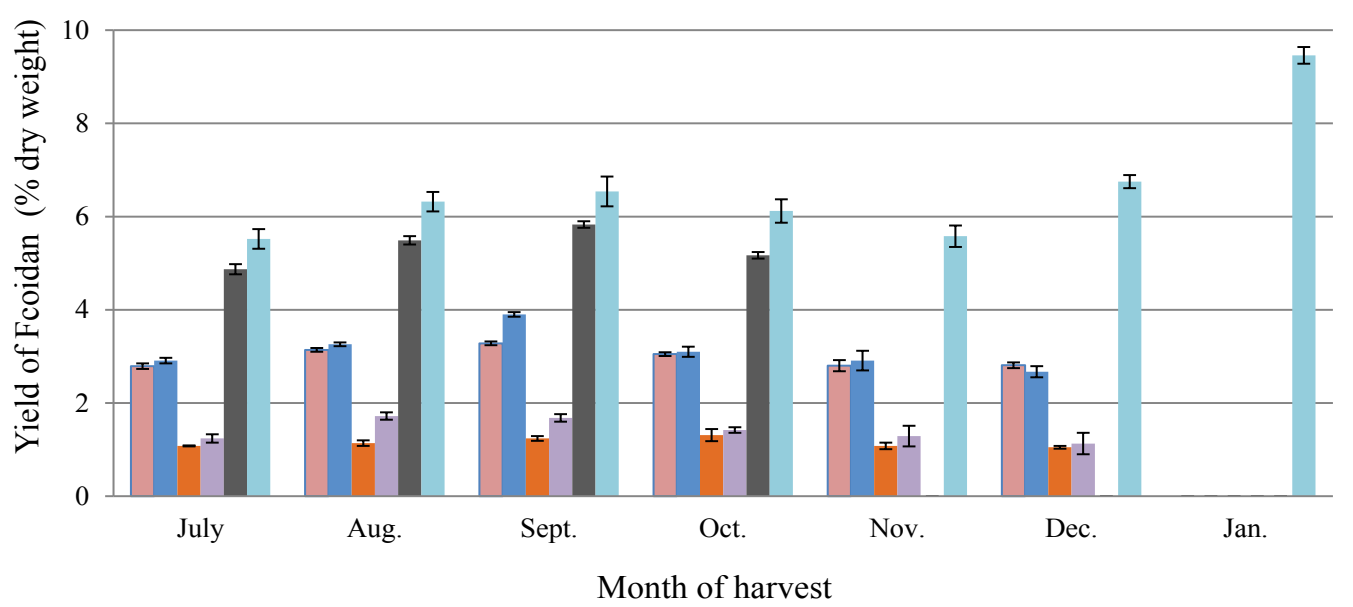

Fig. 1: Variation in the yield of water-extracted crude fucoidan content from brown seaweed species Yield of water extracted crude fucoidan content $(\% \mathrm{~d} / \mathrm{w})$ from brown seaweed species collected at Valinokkam and Hare Island in

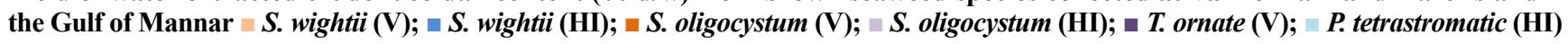




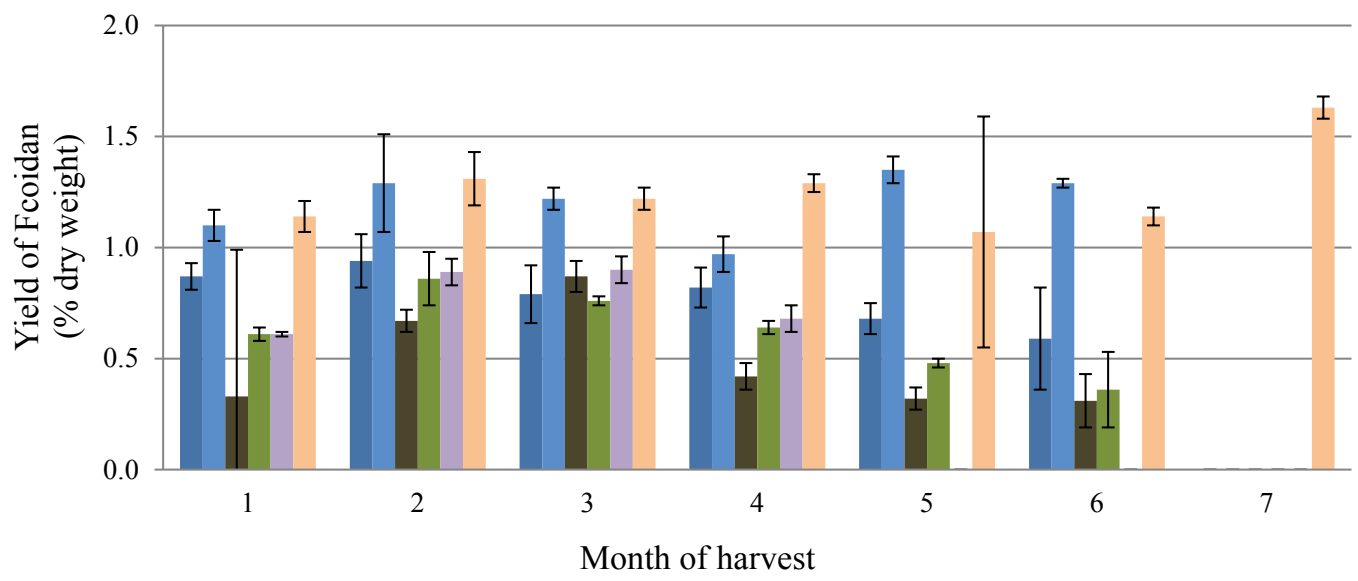

Fig. 2: Monthly variation in the yield of acid-extracted fucoidan content from brown seaweed species

Yield of acid-extracted fucoidan content $(\% \mathrm{~d} / \mathrm{w})$ from brown seaweed species collected at Valinokkam and Hare Island, $\square S$. wightii

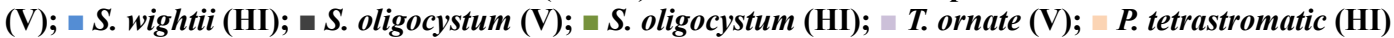

and decreased to $2.81 \pm 0.06 \%$ in December. Similarly, fucoidan extracted from $T$. ornata was found to be $4.87 \pm 0.11$ and $5.83 \pm 0.07 \%$ during July and September, respectively. A similar pattern was observed for other species, S. oligocystum and S. longifolium. Few studies have earlier reported that variations in the yield of fucoidan and its derivatives are affected by the season in which seaweeds are collected ${ }^{[25]}$ and plant maturity ${ }^{[27]}$. The authors also reported a correlation between fucoidan yield and seasonality; and more fucoidan was obtained during the reproductive stages of the seaweed. The physical and chemical states of the seaweed change during the reproductive stage ${ }^{[16]}$. In the present study, Sargassum during maturation period (September and October) gave highest yield of fucoidan and $P$. tetrastromatica collected during January, recorded higher yield. The reproductive receptacles were observed during the month of October for $S$. wightii and T. conoides ${ }^{[28]}$. The highest yield of fucoidan was obtained during January at the maturation stage for $P$. tetrastromatica $(9.46 \pm 0.18 \%)$ of Hare Island and during September, at the maturation stage of T. ornata $(5.83 \pm 0.07 \%)$ of Valinokkam. The maturation stage of $S$. wightii was also September and the highest fucoidan yield of $3.9 \pm 0.05 \%$ at Hare Island. It was also reported that the highest yield of fucoidan from sporophyll of Undaria pinnatifida as 57.3 to $69.9 \%(\mathrm{~d} / \mathrm{w})$ during the maturation stage of alga and also found that the yield varied between the species, comparable to this study ${ }^{[29]}$.

With respect to the yield of fucoidan from the different species of brown seaweeds, it was observed that the yield was higher in $P$. tetrastromatica $(9.46 \pm 0.18 \%)$ collected from Hare Island irrespective of season, than the other species, during water extraction. The yield of fucoidan in $T$. ornata was $(5.83 \pm 0.07 \%)$. The yield of fucoidan was very low in S. oligocystum collected from both the locations. Nevertheless, following acid extraction, the yields of fucoidan from $S$. wightii and $P$. tetrastromatica were found to be more or less similar $(0.87,0.94,0.79 \%$ and $1.14,1.31,1.22 \%)$ during the month of July, August and September, respectively. It was therefore clear that differences in the chemical structure played a role in the yield of fucoidan ${ }^{[12,30,31]}$. Earlier observations also indicated that the variation in the yield of fucoidan due to species, anatomical regions, growing conditions, extraction procedures and analytical methods ${ }^{[30,32]}$. This study also demonstrated that the yield of fucoidan from brown seaweeds varied with species, location, season and method of extraction.

In the present study, biochemical constituents of crude fucoidan such as fucose, sulphate, total free sugars and protein were analysed (Table 1). It was found that fucose was the major constituent of the fucoidan extracted from all the four species. Among the four species, high fucose content was recorded in $P$. tetrastromatica $(54.51 \pm 1.08 \%)$, followed by $T$. ornata $(51.76 \pm 1.43 \%)$. The next major constituent in fucoidan was sulphate, which showed variation among the species similar to fucose. High sulphate content was recorded in $T$. ornata $(24.27 \pm 0.85 \%)$ followed by $P$. tetrastromatica $(22.70 \pm 0.53 \%)$. According to Bilan ${ }^{[31]}$, the extracted fucoidan polymer consisted mainly of carbohydrates (54.9\%) and sulphates (41.5\%) and small amounts of proteins (2.8\%). The sulphate content of crude fucoidan ranged from 5.6 to $42.3 \%$ and fucose from 49.5 to $54 \%$ for $S$. swartzii ${ }^{[33]}$. The values obtained for fucose and sulphate in this study 
TABLE 1: CHEMICAL COMPOSITION OF FUCOIDAN (\%)

\begin{tabular}{lcccc}
\hline Composition (\%) & S. wightii & S. oligocystum & P. tetrastromatica & T. ornata \\
\hline Fucose & $49.34^{\mathrm{b}} \pm 2.78$ & $43.16^{\mathrm{a}} \pm 3.21$ & $54.51^{\mathrm{d}} \pm 1.08$ & $51.76^{\mathrm{c}} \pm 1.43$ \\
Sulphate & $18.73^{\mathrm{b}} \pm 0.82$ & $16.63^{\mathrm{a}} \pm 0.62$ & $22.70^{\mathrm{c}} \pm 0.53$ & $24.27^{\mathrm{d}} \pm 0.85$ \\
Free sugars & $11.39^{\mathrm{c}} \pm 1.03$ & $10.96^{\mathrm{b}} \pm 0.99$ & $11.83^{\mathrm{d}} \pm 1.53$ & $10.17^{\mathrm{a}} \pm 0.23$ \\
Protein & $1.30^{\mathrm{c}} \pm 0.31$ & $0.96^{\mathrm{a}} \pm 0.04$ & $1.14^{\mathrm{bc}} \pm 0.12$ & $1.05^{\mathrm{ab}} \pm 0.15$ \\
\hline
\end{tabular}

Each value is the mean of three observations. Mean bearing at least one common superscript within a row do not differ significantly $(P<0.05)$

were more or less similar to those ranges reported by Chattopadhyay ${ }^{[3]}$ who have extracted fucoidan from Indian brown seaweed, $T$. conoides with fucose $(56 \%)$ and other sugars such as glucose, galactose and xylose. According to Yang ${ }^{[15]}$ monosaccharide composition analysis showed that fucose was the major sugar (78.8\%) and considerable amount of galactose $(21.2 \%)$ was also present in extracted fucoidan. The variation in the monosaccharide composition of fucoidan from $U$. pinnatifida and was analysed and reported that sulphated galactofucan varied from 19 to $38 \mathrm{~mol}$. Percent galactose dependent on the maturity stage of algae $^{[16]}$.

In the present study, the content of total carbohydrates was estimated to be in the range of $10-11 \%$ in all the species of seaweeds. These values corroborate with the results of Rodriguez-Jasso et al. ${ }^{[22]}$ who reported that the total free sugars in fucoidan polymers extracted from $T$. turbinata, S. filipendula and $P$. perindusiata were $9.0,8.9$ and $10.2 \%$, respectively. There were no significant differences observed between the species with respect to total free sugars and protein content $(\mathrm{P}>0.05)$. The protein content ranged between 1.3 and $2.3 \%$, which was quite higher than the value reported for pure fucoidan ${ }^{[34]}$. This study thus indicated that the biochemical composition of fucoidan is significantly different among the species. The variation in the composition of fucoidan also has a large impact on the final structure of fucoidan ${ }^{[12,30,31]}$.

The characterization of the fucoidan structure of the two dominant brown seaweeds viz., P. tetrastromatica and $S$. oligocystum was performed by FT-IR analysis (figs. 3 and 4). A major band centered around 3448.03 $\mathrm{cm}^{-1}$ was assigned to be hydrogen bonded $\mathrm{O}-\mathrm{H}$ stretching vibration in both the species. A weak signal at wavelength $2103.7 \mathrm{~cm}^{-1}$ indicating the presence of $\mathrm{C}=\mathrm{C}=\mathrm{O}$ was noticed in $P$. tetrastromatica only. Another major band at $1688 \mathrm{~cm}^{-1}$ corresponding to the asymmetric stretching of O-C-O vibration was noticed in the fucoidan of both the seaweeds. A minor band at around $1436.69 \mathrm{~cm}^{-1}$ and another two peaks around $1202.64 \mathrm{~cm}^{-1}$ and $140 \mathrm{~cm}^{-1}$ were characteristic of fucoidan in both the species. The peak at $1202 \mathrm{~cm}^{-1}$ corresponded to the $\mathrm{C}-\mathrm{H}$ deformation vibration of $\beta$-manuronic residues. The presence of sulphate groups in fucoidan is very important as it is related to its bioactive properties ${ }^{[15]}$. The sulphate absorption bands at $800 \mathrm{~cm}^{-1}$ and above indicates that most sulphate groups are located at positions 2 and 3 of sugars ${ }^{[35]}$.

FT-IR is frequently used to determine the position of a sulphate group in any bioactive molecule like fucoidan. In the present spectra, a band at $843.78 \mathrm{~cm}^{-1}$ corresponded to the $\mathrm{S}=\mathrm{O}$ stretching vibration of $P$. tetrastromatica and at $842.18 \mathrm{~cm}^{-1}$ of $S$. oligocystum. The IR spectra of fucoidans from brown algae such as Laminaria cichorioides, Fucus evanescens and $L$. japonica showed that most sulphate groups were in axial positions and the remainder were in equatorial positions according to a strong band at $842 \mathrm{~cm}^{-1}$ and a shoulder at $820 \mathrm{~cm}^{-1}$ in the spectra ${ }^{[27]}$. In the present study, the shoulder band appeared at around 803.4 $\mathrm{cm}^{-1}$ but was found at equal concentrations to that of the band at around $842 \mathrm{~cm}^{-1}$, indicating that sulphate groups are present at equivalent amounts in axial and equatorial positions. Another two bands that appeared at 723.03 and $601 \mathrm{~cm}^{-1}$ seem to be characteristic of C-O-S stretching of sulphate group and $\mathrm{C}=\mathrm{C}-\mathrm{H}$ stretching vibration, respectively in both the species of seaweeds. As discussed earlier, the major differences among the species were the presence of a minor band at $2103.73 \mathrm{~cm}^{-1}$ in $P$. tetrastromatica and slight shifts noticed in sulphate group band. Besides this, the structure of fucoidan extraction from the two seaweeds was more or less similar.

In conclusion, two brown seaweed species viz., $P$. tetrastromatica and T. ornate collected along the Gulf of Mannar coast were found to be the major source of fucoidan. Water extraction procedure provided high yield of fucoidan irrespective of the species. High yielding seaweed, $P$. tetrastromatica was dominant in Hare Island, while T. ornata was dominant in Valinokkam area. Yield of fucoidan was higher during maturation stage, which was September for T. ornata and S. wightii; and January for P. tetrastromatica. 
www.ijpsonline.com

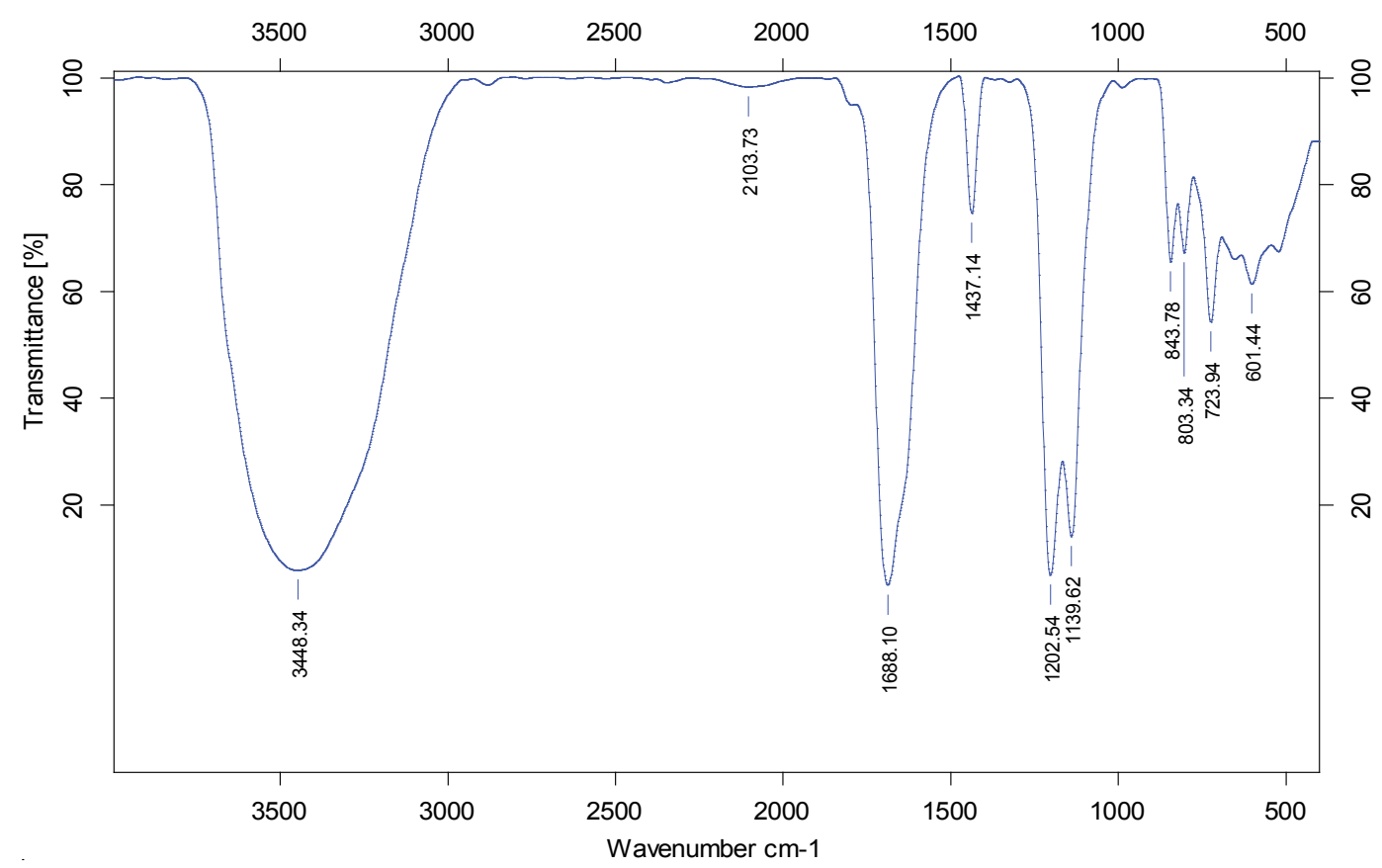

Sample Name: PT-I

Fig. 3: FTIR analysis of fucoidan extracted from brown seaweed P. tetrastromatica

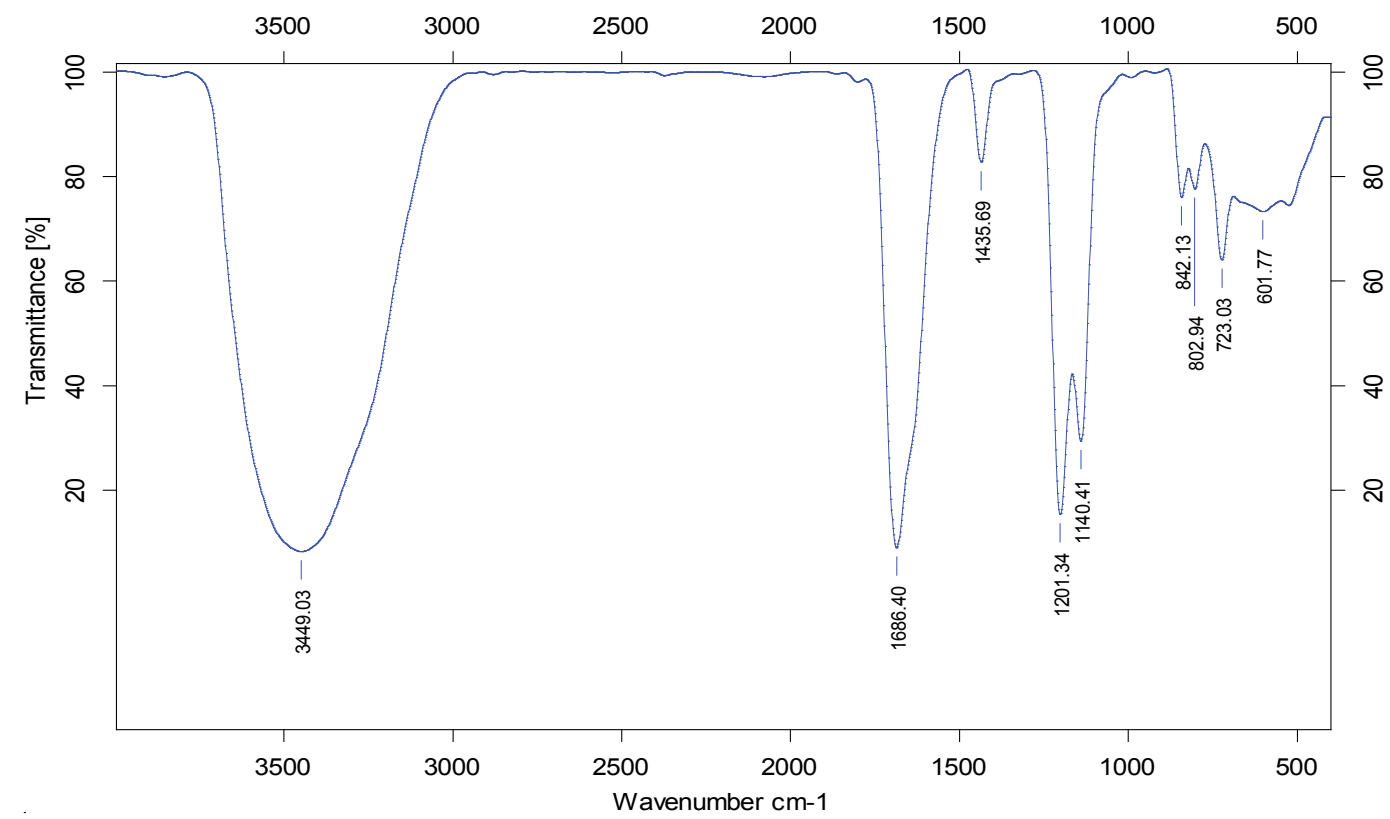

Sample Name: SL-I

Fig. 4: FTIR analysis of fucoidan extracted from brown seaweed $S$. oligocystum

Fucoidan of $P$. tetrastromatica has high source of fucose and $T$. ornata has high sulphate. Structurally there is no significant difference in the functional groups of fucoidan extracted from these two major seaweed species. This study thus interferes that there is a tremendous resource potential for fucoidan yielding seaweeds in the Gulf of Mannar, which shall be explored further to examine their bioactive potential to suit for food and pharmaceutical applications.
Acknowledgements:

The financial assistance from Tamilnadu Veterinary and Animal Sciences University, Chennai is gratefully acknowledged.

\section{Conflict of interest:}

There are no conflicts of interest.

Financial support and sponsorship:

Nil. 


\section{REFERENCES}

1. Ale MC, Jorn D, Mikkelsen, Meyer AS. Important determinants for fucoidan bioactivity: A critical review of structure-function relations and extraction methods for fucose containing sulfated polysaccharides from brown seaweeds. Mar Drugs 2011;9:2106-30.

2. Krishnamoorthy V, Ezhili R. Phaeophyceae of India. Neighbourhood 2013;2:1-156.

3. Chattopadhyay N, Ghosh T, Sinha S, Chattopadhyay K, Karmakar P, Ray B. Polysaccharides from Turbinaria conoides: Structural features and antioxidant capacity. Food Chem 2010;118:823-9.

4. Nishino T, Nishioka C, Ura H, Nagumo T. Isolation and partial characterization of a novel amino sugar-containing fucan sulfate from commercial Fucus vesiculosus fucoidan. Carbohydr Res 1994;255:213-24.

5. Qiao J. Antibacterial effect of extracts from two Icelandic algae (Ascophyllum nodosum and Laminaria digitata). Final Project 2010;1-37.

6. Synytsya A, Kim EWJ, Kim ESM, Radek Pohl D, Synytsya BA, Kvasnicka CF, et al. Structure and antitumour activity of fucoidan isolated from sporophyll of Korean brown seaweed Undaria pinnatifida. Carbohydr Polym 2010;81:41-8.

7. Usov AI, Smirnova, Klochkova NG. Polysaccharides of algae: Polysaccharide composition of several brown algae from Kamchatka. Russ J Bio Organ Chem 2001;27:395-9.

8. Immanuel G, Velmurugan MS, Marudhupandi $T$, Radhakrishnan S, Palavesam A. The effect of fucoidan from brown seaweed Sargassum wightii on WSSV resistance and immune activity in shrimp Penaeus monodon (Fab). Fish Shellfish Immunol 2012;32:551-64.

9. Percival E, McDowell RH. Chemistry and Enzymology of Marine Algal Polysaccharides. London and New York: Academic Press; 1967.

10. Hahn T, Kelly S, Muffer K, Tippkotter N, Ulber R. Extraction of lignocelluloses and algae for the production of bulk and fine chemicals. In: Hans-Jorg B, Stephen P, editors. Industrial Scale Natural Products Extraction. Weinheim: Wiley-VCH Publishers; 2011. p. 45.

11. Bilan MI, Grachev AA, Shashkov AS, Nifantiev NE, Usov AI. Structure of a sulphated fucan from the brown seaweed Fucus serratus. L. Carbohydr Res 2006;341:238-45.

12. Duarte MER, Cardoso MA, Noseda MD, Cerezo AS. Structural studies on fucoidans from the brown seaweed Sargassum stenophylum. Carbohydr Res 2001;333;281-93.

13. Marais MF, Joselean MP. A fucoidan fraction from Ascophyllum nodosum. Carbohydr Res 2001;336:155-9.

14. Rioux LE, Turgeon SL, Beaulieu M. Characterization of polysaccharides extracted from brown seaweeds. Carbohydr Polym 2007;69:530-7.

15. Yang C, Chung D, You SG. Determination of physicochemical properties of sulphated fucans from sporophyll Undaria pinnatifida using light scattering technique. Food Chem 2008;111:503-7.

16. Skriptsova, AV, Shevchenko NM, Zvyagintseva TN, Imbs TI. Monthly changes in the content and monosaccharide composition of fucoidan from Undaria pinnatifida (Laminariales, Phaeophyta). J Appl Phycol 2010;22:79-86.

17. Gupta S, Abu-Ghannam N. Bioactive potential and possible health effects of edible brown seaweeds. Trends Food Sci Technol 2011;22:315-26.
18. Dodgson KS, Price RG. A note on the determination of the ester sulphate content of sulphated polysaccharides. J Biochem 1962;84:106-10.

19. Dische Z, Shettles LB. A specific colour reaction of methyl pentoses and of macrophages. Pathobiology 1948;67:222-6.

20. Carroll NV, Longley RW, Roe JH. The determination of glycogen in liver and muscle by use of anthrone reagent. J Biol Chem 1955;583-93.

21. Bradford MM. A rapid and sensitive for the quantitation of microgram quantities of protein utilizing the principle of protein-dye binding. Anal Biochem 1976;72:248-54.

22. Rodriguez-Jasso RM, Mussatto SI, Pastrana L. Extraction of sulphated polysaccharides by auto hydrolysis of brown seaweed Fucus vesiculosus. J Appl Phycol 2013;25:31-9.

23. Rani V, Jawahar P, Jeya Shakila R. Seasonal variation in biomass and distribution of brown seaweeds (Phaeophyceae) in Gulf of Mannar, Tamilnadu, India. The Bioscan 2015;10:1123-9.

24. Holtkamp A, Kelly S, Ulber R, Lang S. Fucoidan and Fucoidanases - Focus on techniques for molecular structure elucidation and modification of marine polysaccharides. Appl Microbiol Biotechnol 2009;82:1-11.

25. Honya M, Mori H, Anzai M, Araki Y, Nisizawa K. Monthly changes in the content of fucans, their constituent sugars and sulphate in cultured Laminaria japonica. Hydrobiologia 1999;398:411-6.

26. Mak WWF. Extraction, Characterization and Antioxidant Activity of Fucoidan from New Zealand Undaria pinnatifida (Harvey) Suringar. Master Degree Thesis, Auckland, New Zealand: Auckland University of Technology; 2012. p.104.

27. Zuyagintseva TN, Shevchenko NM, Chiznova AO, Krupnova TN, Sundukova KV, Isakov VV. Water-soluble polysaccharides of some far-eastern brown seaweed, Distribution, structure and their their dependence on the developmental conditions. J Exp Mar Biol Ecol 2003;294:1-13.

28. Umamaheswara R. Seaweed Resources of India-Souvenir20th Anniversary. Central Marine Fisheries Research Institute (Government of India). CMFRI Recreation Club, Mandapam; 1969.

29. Mak WN, Hamid Liu T, Lu J, White WL. Fucoidan from New Zealand Undaria pinnatifida: Monthly variations and determination of antioxidant activities. Carbohydr Polym 2013;95:606-14.

30. Chizhov AO, Dell A, Morris HR, HaslamSM, McDowell RA, Shashkov AS, et al. A study of fucoidan from the brown seaweed Chorda filum. Carbohydr Res 1999;320:108-19.

31. Bilan MI, Grachev AA, Ustuzhamina NE, Shashkov AS, Nifantiev NE, Usov AI. Structure of fucoidan from the brown seaweed Fucus evanescens. Carbohydr Res 2002;337:719-30.

32. Ponce NM, Pujol CA, Damonte E.B. Fucoidans from the brown seaweed Adenocystis utricularis: Extraction methods, antiviral activity and structural studies. Carbohydr Res 2003;338:153-65.

33. Ly BM, Buu NQ, Nhut ND, Thinh PD, Van TT. Studies on fucoidan and its production from vietnamese brown seaweeds. Asian J Sci Technol Develop 2005;22:371-80.

34. Hayakawa K, Nagamine T. Effect of Fucoidan on the biotinidase kinetics in human hepatocellular carcinoma. Anticancer Res 2009;29:1211-7.

35. Percival E, Wold JK. The acid polysaccharide from the green seaweed Ulva lactuca, Part II. The site of the ester sulphate. J Chem Soc 1963;5459-68. 